\title{
A Modulatory Proctolin-Containing Neuron (MPN). I. Identification and Characterization
}

\author{
Michael P. Nusbaum ${ }^{\mathrm{a}}$ and Eve Marder \\ Department of Biology, Brandeis University, Waltham, Massachusetts 02254
}

\begin{abstract}
The pentapeptide proctolin has been localized previously to the crustacean stomatogastric nervous system and shown to modulate the rhythmic activity of the pyloric network in the stomatogastric ganglion (STG) (Marder et al., 1986; Hooper and Marder, 1987). We have now identified a pair of modulatory proctolin-containing neurons (MPNs) that cause proctolin-like modulation of the pyloric rhythm. Individual MPNs were identified by combining intracellular Lucifer yellow dye injection with rhodamine-visualized proctolin immunolabeling. Both MPNs are located in the esophageal nerve and send processes to the STG. Current injection into one MPN influences the second MPN, suggesting that they are electrically coupled. The 2 MPNs have similar effects on the pyloric rhythm of the STG. Intracellular stimulation of a single MPN was sufficient to enhance already active pyloric rhythms and initiated the pyloric rhythm in quiescent preparations.
\end{abstract}

Our goal is to understand how neurally released peptides modulate rhythmically active neural networks. Whereas much attention has been focused on the widespread localization of neuropeptides and their modulatory effects on individual neurons (Krieger et al., 1983; O'Shea and Schaffer, 1985; Polak and Bloom, 1987), considerably less is known about peptidergic modulation of neural networks. Thus far, most such studies have employed exogenously applied neuropeptides (Mackey and Carew, 1983; Hooper and Marder, 1984, 1987; Dekin et al., 1985; Murphy et al., 1985; Marder et al., 1986; Mulloney et al., 1987; Sossin et al., 1987; Nusbaum and Marder, 1988a).

While the actions of an endogenously released neuropeptide may be well mimicked by exogenous application of the substance, this is not necessarily the case. Endogenously released and exogenously applied neuropeptide can affect the same target differently, for a number of reasons. For example, there may be differences in access to receptors, effective concentrations, rates of delivery, and/or extent of inactivation. Each of these factors will influence how a neuron will respond to peptide application. The possible discrepancy between endogenous and exogenous application may be further exacerbated when studying the response of a neural network to a peptide, since different neuronal targets may be affected in the 2 cases. Additionally, many neu-

\footnotetext{
Received Aug. 15, 1988; revised Oct. 18, 1988; accepted Oct. 19, 1988.

We thank Drs. M. R. O'Shea and C. A. Bishop and Dr. N. T. Davis for generously supplying us with anti-proctolin antibodies. Mr. Michael O'Neil provided us with invaluable technical assistance, and Ms. Wanita Kumar assisted with preparations of the figures. Supported by NRSA NS-07446 (M.P.N.) and NS-17183.

Correspondence should be addressed to Dr. Eve Marder at the above address.

a Present address: Department of Biology, San Francisco State University, 1600 Holloway Avenue, San Francisco, CA 94132.

Copyright (c) 1989 Society for Neuroscience 0270-6474/89/051591-09\$02.00/0
}

rons contain more than one neurotransmitter (Hökfelt et al., 1987). Therefore, exogenously applying a neuropeptide would not necessarily mimic the effects of stimulating the peptidergic neuron because the effects of the neurally released peptide might normally be intertwined with those of one or more co-released substances.

Thus far, only a few studies have examined this issue, and they have focused on individual neuronal targets, not neuronal ensembles. For example, bath-applied proctolin and stimulation of a proctolinergic motor neuron both enhance tonic muscle tension in the cockroach (Adams and O'Shea, 1983) and crayfish (Bishop et al., 1987). In leech muscle, both exogenous FMRFamide and activity in FMRFamide-containing neurons increase rhythmic beat tension and/or induce a myogenic rhythm (Kuhlman et al., 1985; Li and Calabrese, 1987). Within the nervous system, long-term changes in neuronal excitability caused by stimulating peptidergic neurons are mimicked by externally applied peptide in both vertebrates and invertebrates (Jan et al., 1983; Sigvardt et al., 1986). In most cases, however, the neurons responsible for peptidergic effects within the CNS have not been physiologically identified.

The pyloric system of the crustacean stomatogastric ganglion (STG) has served as a model for understanding both how neural networks generate rhythmic motor patterns (Selverston and Moulins, 1987) and how these activity patterns are modulated by different, exogenously applied neuroactive substances (Marder, 1987). Many modulatory inputs, including several that contain neuropeptides, enter the STG from the stomatogastric nerve $(\mathrm{s}(\mathrm{n})$ and affect the pyloric rhythm. Neuropeptides contained in inputs to the STG include proctolin (Hooper and Marder, 1984, 1987; Marder et al., 1986), a FMRFamide-like peptide (Hooper and Marder, 1984; Callaway et al., 1987; Marder et al., 1987), a cholecystokinin-like peptide (Turrigiano and Selverston, 1987), a small cardioactive peptide $\mathrm{B}$-like ( $\mathrm{SCP}_{\mathrm{b}}$-like) peptide (Callaway et al., 1987), a red-pigment concentrating hormone-like peptide (Nusbaum and Marder, 1988a), and a substance P-like peptide (Goldberg et al., 1988).

The pentapeptide proctolin is the best-characterized peptide modulator of the pyloric rhythm. Proctolin has been localized, immunocytochemically and biochemically, to the neuropil of the STG and to cells and neuropil in the esophageal ganglion (OG) and the paired commissural ganglia (CGs) (Marder et al., 1986). When proctolin is bath-applied $\left(10^{-9}\right.$ to $\left.10^{-6} \mathrm{M}\right)$ to the isolated STG, the pyloric rhythm is activated in quiescent preparations and enhanced in alrcady rhythmically active preparations (Hooper and Marder, 1984, 1987; Marder et al., 1986). The direct pyloric targets of proctolin have been identified in the lobster, Panulirus interruptus (Hooper and Marder, 1987). 


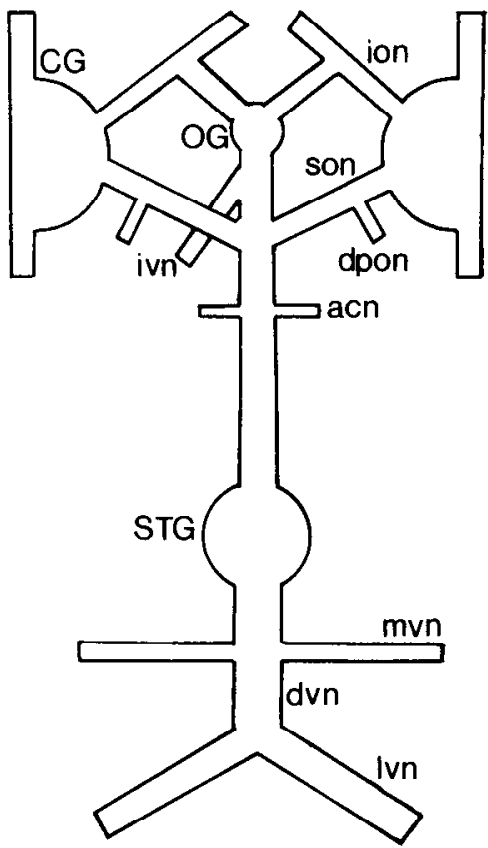

Figure 1. Schematic diagram of the stomatogastric nervous system. Abbreviations: $a c n$, anterior cardiac nerve; $C G$, commissural ganglion; $d p o n$, dorsal posterior esophageal nerve; $d v n$, dorsal ventricular nerve; ion, inferior esophageal nerve; ivn, inferior ventricular nerve; $l v n$, lateral ventricular nerve; $m v n$, medial ventricular nerve; $O G$, esophageal ganglion; son, superior esophageal nerve; $S T G$, stomatogastric ganglion.

Because proctolin immunolabeling is present in fine processes and swellings within the STG neuropil, it is likely that proctolin is neurally released within the STG neuropil. To determine both the source of the proctolin-containing innervation of the STG and whether neurally released proctolin is well-mimicked by exogenously applied proctolin, we searched for, and identified, proctolin-containing neurons that extend to the STG and excite the pyloric rhythm.

In this paper we report the identification and characterization of a pair of apparently homologous, modulatory proctolin-containing neurons (MPNs) that extend processes to the STG from their somata in the OG. In the accompanying paper (Nusbaum and Marder, 1989), the effects of MPN stimulation on the pyloric rhythm are described and compared with those produced by bath-applied proctolin. Some of these data have been presented in abstract form (Nusbaum and Marder, 1987, 1988b).

\section{Materials and Methods}

Animals. Cancer borealis were obtained from local (Boston) commercial fishermen and held in artificial seawater aquaria until used. Data were obtained from 33 male animals weighing between 100 and $500 \mathrm{gm}$.

Solutions. C. borealis physiological saline had the following composition (mM/liter): $\mathrm{NaCl}, 440 ; \mathrm{KCl}, 11 ; \mathrm{MgCl}_{2}, 26 ; \mathrm{CaCl}_{2}, 13$; Trizma Base, 10; maleic acid, 5.0; $\mathrm{pH} 7.4-7.5$. Proctolin was obtained from Sigma and kept as a frozen, aliquoted stock solution $\left(10^{-2} \mathrm{M}\right)$. Aliquots were diluted to desired concentration in physiological saline immediately before use.

Anatomy and immunocytochemistry. Whole-mount immunocytochemistry on the stomatogastric nervous system was performed by the method of Beltz and Kravitz (1983) as described previously (Marder et al., 1986, 1987). The primary antiserum used for most of this work, a rabbit anti-proctolin antibody, was a gift from Drs. C. A. Bishop and M. R. O'Shea and has been characterized previously (Bishop et al., 1981). More recently, we have used a rabbit anti-proctolin antibody provided by Dr. N. T. Davis (Davis et al., 1989). The Davis antibody gave a very similar staining pattern to the Bishop-O'Shea antibody, and both stained the same 3 neurons in the OG. Both antibodies were used at a dilution of 1:600. Because the anti-proctolin antibody labels a peptide in the stomatogastric nervous system that is chromatographically indistinguishable from authentic proctolin (Marder et al., 1986), we refer to the cells and fibers that label with this antibody as "proctolincontaining."

Lucifer yellow (LY) backfills of the stn were performed as described in Marder et al. (1987), with the exception that the concentration of LY was raised to $15-20 \%$. Intracellular injections of LY-CH were carried out using $\mathrm{LY}$-filled ( $5 \%$ in distilled water, backfilled with $1.0 \mathrm{M} \mathrm{LiCl}$ ) microelectrodes. LY was iontophoresed using hyperpolarizing current pulses (approximately 3-5 nA) of $500 \mathrm{msec}$ duration at $1 \mathrm{~Hz}$ frequency. LY-filled preparations used for double labels with anti-proctolin antibody were fixed in $4 \%$ paraformaldehyde (in $0.1 \mathrm{M} \mathrm{NaPO}_{4}, \mathrm{pH} 7.3$ ) and processed for whole-mount immunocytochemistry as described above. Preparations were viewed using a Zeiss IM35 fluorescence microscope equipped with rhodamine and fluorescein filters.

Electrophysiology. Electrophysiological experiments wcrc performed on in vitro preparations of stomatogastric nervous systems (Fig. 1) in which, unless otherwise noted, activity in both (desheathed) CGs was blocked using a solution containing either isotonic $(750 \mathrm{mM})$ sucrose plus $10^{-6} \mathrm{M}$ TTX or only isotonic sucrose. Both solutions gave the same results. Electrophysiological experiments used routine methods for the STG (Selverston and Moulins, 1987). Extracellular recordings were made using vaseline-insulated stainless steel pin electrodes. Intracellular recordings of STG neurons were made using 20-50 M $\Omega$ potassium acetatefilled or 15-25 M 2 potassium chloride-filled microelectrodes. In many experiments, intracellular recordings of MPN were made using $L Y$-filled microelectrodes with resistances of $40-80 \mathrm{M} \Omega$. A continuously flowing superfusion system $(6-10 \mathrm{ml} / \mathrm{min})$ that permitted rapid changes of the bath solution was used during all experiments. Superfused solutions were cooled to $12-16^{\circ} \mathrm{C}$. Bath volume was $15-20 \mathrm{ml}$.

\section{Results}

\section{Localizing MPN}

The complete stomatogastric nervous system consists of the STG, the OG, and the paired CGs, along with nerves that connect them and those that innervate the foregut muscles (Fig. 1). The STG receives an extensive innervation from proctolin-containing fibers that enter the STG via the stn (Hooper and Marder, 1984; Marder et al., 1986). While there are no proctolin-containing neurons within the STG, several proctolin-containing neurons are located in both the OG and CGs (Marder et al., 1986). Since these ganglia are known to provide inputs to the STG, it was likely that the proctolin-containing terminals in the STG neuropil had somata in the OG or CGs.

To determine whether any of the proctolin-containing OG neurons extended processes to the STG, LY backfills of the stn were combined with proctolin immunocytochemistry. LY backfills of the stn repeatedly labeled $30 \mathrm{O}$ neurons (Fig. $2 A$ ). These included a relatively large neuron (approx. $120 \mu \mathrm{m}$ ) within the OG and a pair of small ncurons (approx. $30 \mu \mathrm{m}$ ), often located near the $O G$ in the esophageal nerve (on). The large, unpaired neuron did not exhibit proctolin immunolabeling, and it is likely to be the cardiac dilator 1 (CD1) motor neuron. In contrast, the 2 small neurons both exhibited proctolin immunolabeling (Fig. $2, B, C)$. Sometimes, 1 of these 2 neurons was located within the OG, and, very rarely, both were in the OG. A third proctolincontaining OG neuron was never filled with LY from stn backfills.

As a result of the double-labeling and electrophysiological experiments to be presented below, the 2 double-labeled neurons were designated the "modulatory proctolin-containing neurons" (MPNs). The 2 MPNs were the only LY-labeled neurons seen in the on following LY backfills of the $\operatorname{stn}(n=6)$. Moreover, it was rare to see any neurons other than the MPNs within the on. In an additional 6 preparations in which the $O G$ was stained 

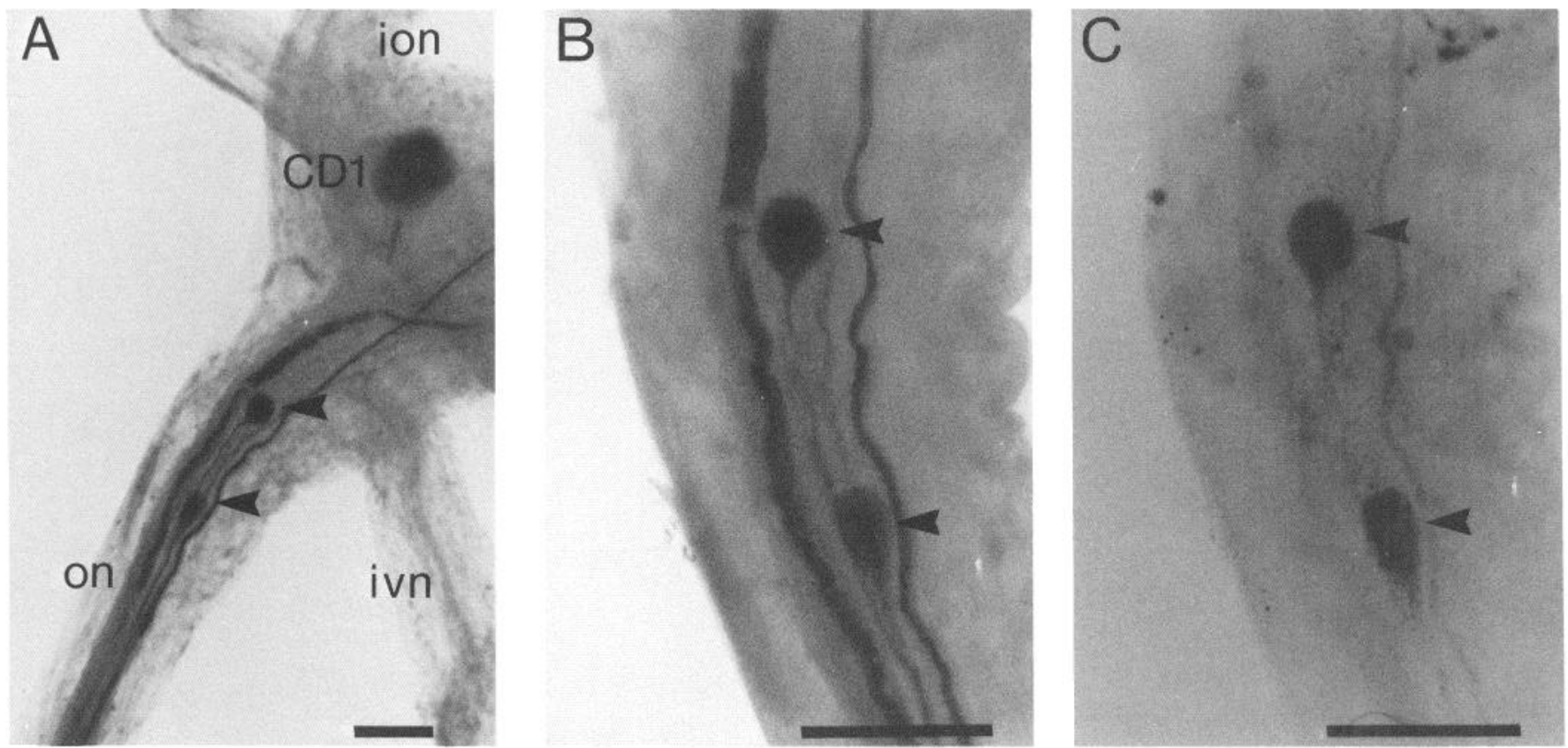

Figure 2. Double-labeled MPNs combining LY-backfilled stn and rhodamine-visualized anti-proctolin immunocytochemistry. A, Low-magnification whole mount of esophageal nerve (on) and esophageal ganglion following LY-backfill of the stn. LY fluorescence is seen in several fibers and 2 somata (approximately $30 \mu \mathrm{m}$ ) within the on (arrowheads) and in a single, larger soma (approximately $120 \mu \mathrm{m}$ ), labeled CD1, within the OG. The stn is towards the lower left. $B$, Higher magnification of the on region from $A$. $C$, Same location, same focal plane as in $B$, viewed with rhodamine optics to reveal anti-proctolin immunoreactivity. Scale bars, $100 \mu \mathrm{m}$.

with methylene blue, either 1 or 2 (presumably MPN) small neurons were seen in the on, while 10-13 neurons were visible within the $O G$, so it became possible to locate routinely the MPNs on the basis of their position. Since the crab OG region has 15-16 neuronal somata (B. J. Claiborne, P. S. Dickinson and E. Marder, unpublished observations), in most preparations most of the OG neurons can be visualized.

Intracellular LY injections into individual MPNs confirmed that each MPN extended processes into the $\operatorname{stn}(n=8)$. As shown in Figure 3, a single process extended from the MPN soma along the on, to the junction of this nerve with the superior esophageal nerves (sons) and the stn. At this junction, the MPN process branched, extending single processes into each son and a pair of processes into the stn. Both MPNs had this same branching pattern. Dye coupling was never observed between these 2 neurons. The distance from the MPN soma to the STG is approximately $1 \mathrm{~cm}$, and thus far it has not been possible to inject sufficient dye into an MPN soma to visualize its arborization in the STG. The LY injections, however, were usually sufficient to label the stn processes of MPN past the junction of the stn with the anterior cardiac nerve (acn in Fig. 1), the only stn branch between the son and the STG. Additionally, the electrophysiological experiments (below) strongly suggest that MPN does extend to the STG.

These LY-filled neurons contained proctolin as shown by subsequently processing each preparation for whole-amount proctolin immunocytochemistry (Fig. 4). Double-labels were performed on most of the preparations used for the electrophysiological experiments presented below, and they served to confirm the identity of MPN in these experiments.

\section{MPN impulse activity}

Using the results from intracellular LY fills of MPN as a guide, extracellular recordings were made from various nerves to iden- tify pathways in which MPN impulses could be recorded. As expected from the LY fills, extracellularly recorded impulses that were time-locked to intracellular MPN impulses were observed in both sons (Fig. 5A). MPN impulses were also recorded bilaterally in the dorsal posterior esophageal nerve (dpon), a peripherally directed branch of the sons (Fig. $5 A$ ). The MPN impulse in each son could also be recorded distal to the branch point of the dpon, suggesting that MPN extended a process into each CG. MPN action potentials were detected in the stn after desheathing the nerve, although not before (Fig. $5 B$ ). The threshold for extracellular activation of MPN was always more than 10-fold higher than that required for the lowest threshold units in the stn or son, presumably because the MPN axons are smaller than those of the largest fibers in those nerves. The latency from impulse generation in the MPN soma to its arrival at the son and stn extracellular electrodes in Figure $5 B$ was very similar (13-15 msec).

In most preparations (20/21), MPN was either quiescent or exhibited relatively slow, tonic impulse activity $(<3 \mathrm{~Hz})$ (Fig. $5 C$ ). This activity pattern was seen regardless of whether the preparation consisted of only the OG connected to the STG or also included the CGs. This tonic pattern tended to be unaffected by the activity of pyloric and esophageal rhythms. In one experiment, MPN exhibited rhythmic activity that was time-locked to the pyloric rhythm.

Stable, long-term (several hours) intracellular recordings from MPN exhibited resting potentials of -40 to $-60 \mathrm{mV}$. Two different amplitude potentials were routinely recorded from the MPN soma. One was nearly overshooting (amplitude, 40-50 $\mathrm{mV}$ ) and is clearly an orthodromic action potential since intrasomatic current injection always elicited the large-amplitude spike. This large spike was also elicited antidromically by single suprathreshold shocks to the stn. The other event routinely recorded in MPN somata was considerably smaller and con- 

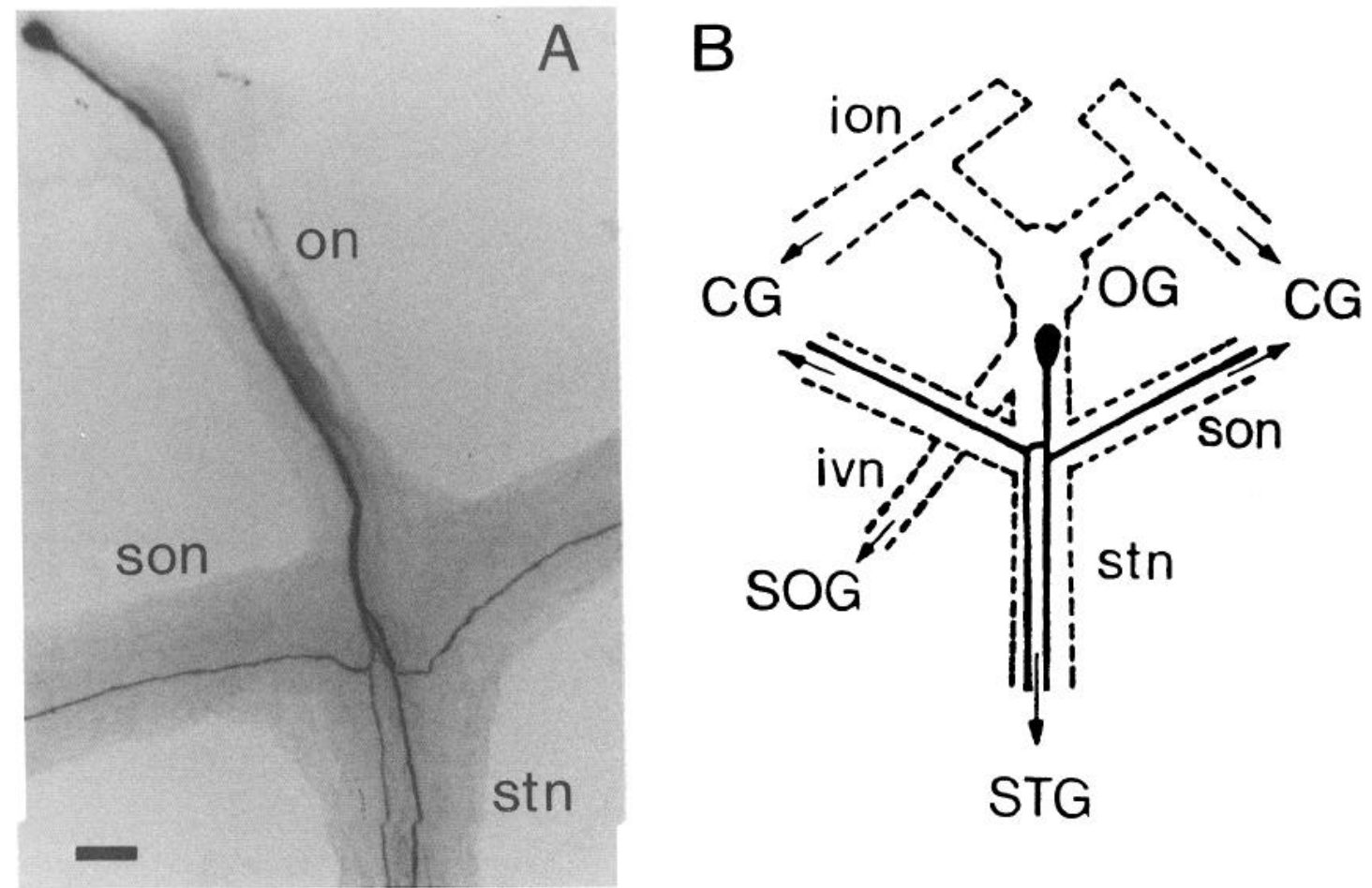

Figure 3. Intracellular LY-fill of a single MPN. $A$, LY-labeled MPN soma in the on. Primary neurite branches at the junction of the on with the sons and stn, extending single processes into each son and 2 processes into the stn. Scale bar, $100 \mu \mathrm{m}$. $B$, Schematic diagram of proximal branching pattern of MPN. SOG, supraesophageal ganglion. All other abbreviations as in Figure 1.

sisted of approximately $4-8 \mathrm{mV}$ depolarizing potentials (Fig. $5 C$ ). These small amplitude potentials were elicited by electrical shocks to the son. Stimulating the son, at the same intensity, sometimes elicited the large-amplitude spikes and sometimes elicited the small-amplitude potentials with the same latency. Repeated shocks to the son resulted primarily in the appearance of the smaller-amplitude potentials. Since the LY fills show that MPN has an axon in the sons, it is possible that the smallamplitude potentials are spikes generated in a distant spikeinitiating zone that fail to be actively propagated into the soma. Despite the apparent occurrence of electrical coupling between the MPNs (see below), the small-amplitude spikes were not coupling potentials from one MPN to the other.

\section{Electrical coupling between the two MPNs}

The 2 MPNs were apparently electrically coupled. When a single MPN was stimulated, the impulse activity of the unstimulated MPN increased, although to a lesser extent than that of the stimulated MPN (Fig. 6). Moreover, depolarizing coupling potentials were observed in each MPN that correlated with the action potentials of the other MPN (data not shown). Intracellular injection of hyperpolarizing current into one MPN resulted in a small hyperpolarization and a decreased firing frequency in the uninjected MPN (Fig. 6), thus reinforcing the interpretation that the 2 MPNs are electrically coupled.
Figure 4. Double-labeled MPN combining intracellular LY-fill and antiproctolin immunocytochemistry. $A$, High-magnification view of MPN soma (solid arrowhead) and initial neurite filled intracellularly with LY. The other, unfilled, MPN is also faintly visible (open arrowhead). B. Same focal plane as $A$ but viewed with rhodamine optics to reveal anti-proctolin immunolabeling in LY-filled MPN (solid arrowhead) as well as neighboring, unfilled MPN soma (open arrowhead). The OG is towards the top; the stn towards the bottom. Scale bars, $100 \mu \mathrm{m}$.
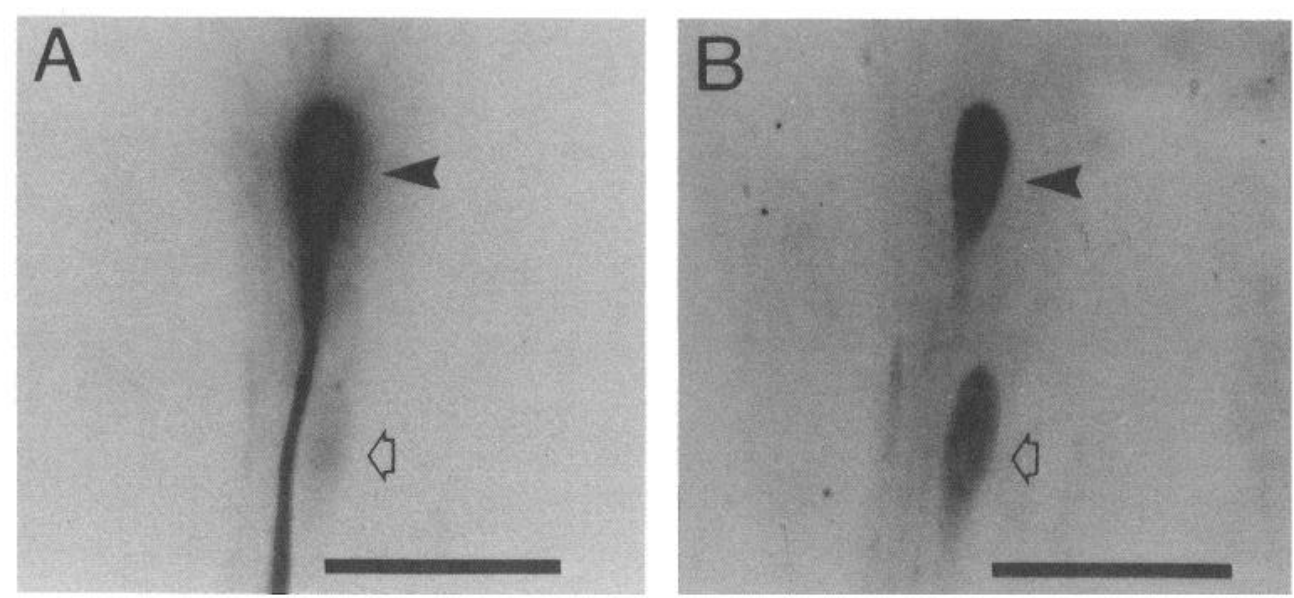

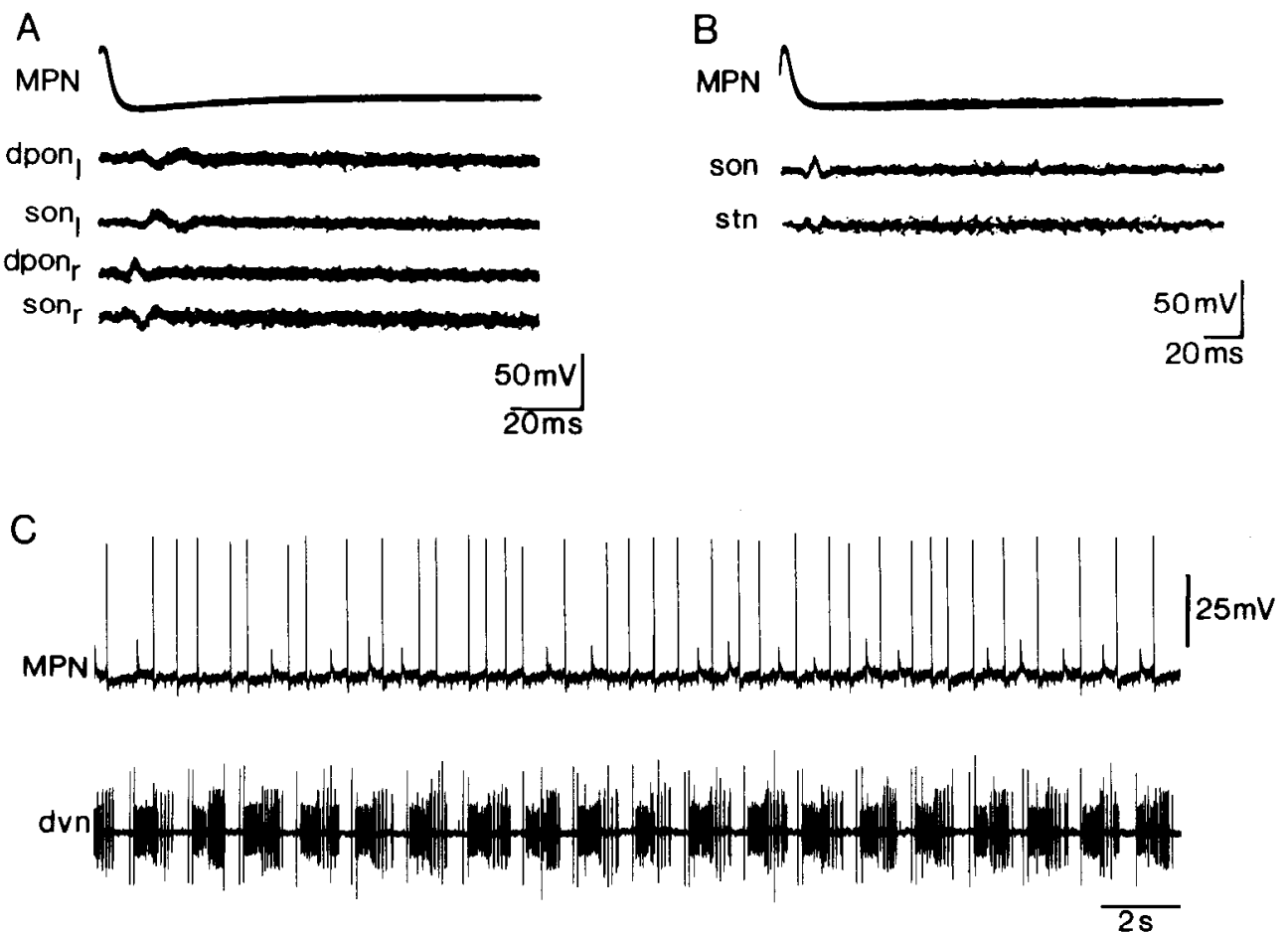

$50 \mathrm{mv}$

$20 \overline{\mathrm{ms}}$

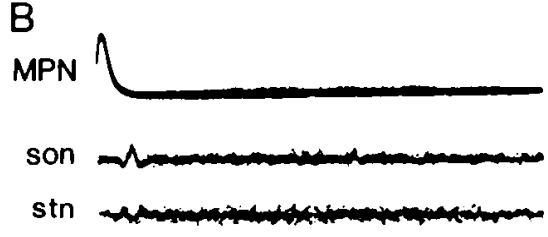

Figure 5. MPN impulse pathways. $A$, Superimposed sweeps, triggered by MPN impulses elicited by intracellular injection of depolarizing current, show time-locked impulses in both sons and both dpons. son electrodes placed near the respective dpons; dpon electrode placement near its connection with son. $B$. Extracellular impulses in the son and stn time-locked to MPN soma impulses elicited by intracellularly injected depolarizing current. stn electrode placement approximately halfway between STG and the stn junction with the on and sons. $C$, Tonic impulse activity in spontaneously active MPN during ongoing pyloric rhythm. Preparation included the STG and OG and their connecting and motor nerves. $M P N$ resting potential was $-50 \mathrm{mV}$. Panels $A-C$ were from different preparations.

\section{MPN impulse activity excites the pyloric rhythm}

Stimulating MPN intracellularly caused excitation of the pyloric rhythm. When MPN was spontaneously active, hyperpolarization with intracellularly injected current decreased the frequency of the pyloric rhythm. The recordings shown in Figure 7 illus- trate the effects of MPN stimulation on the pyloric rhythm in an active preparation. The top 2 traces in Figure 7 (lvn and mvn) are extracellular recordings from 2 of the motor nerves exiting the STG (Fig. 1). These recordings show repeating bursts of action potentials in the motor neurons that innervate the pyloric region muscles. The third trace in Figure 7 is an intra-
A

$\mathrm{MPN}_{1}$

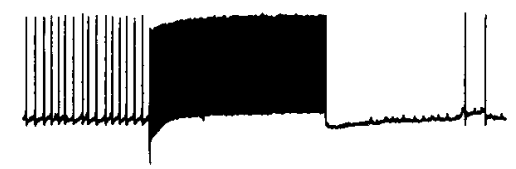

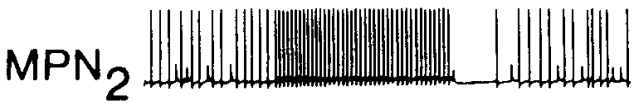

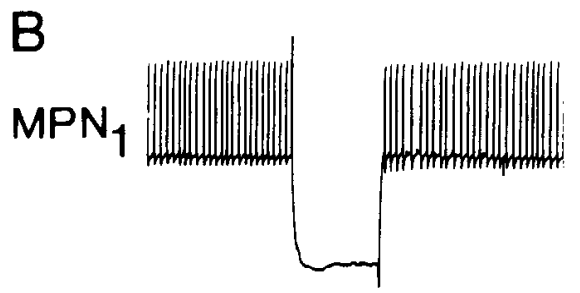

MPN2
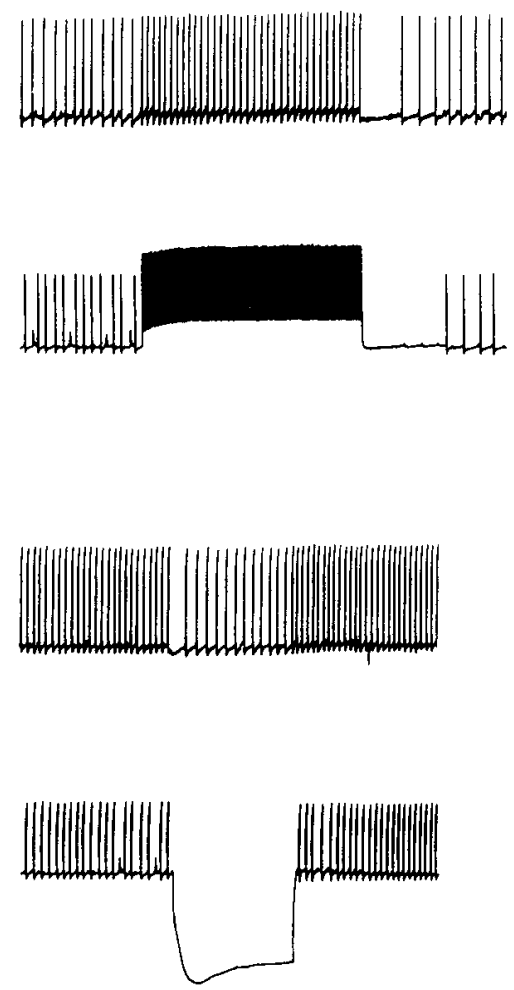

Figure 6. Apparent electrical coupling between the 2 MPNs. $A$, Intracellularly stimulating either MPN $(+1 \mathrm{nA})$ via the recording electrode increases firing frequency in the unstimulated MPN. $B$, Intracellular hyperpolarizing current $(-3 \mathrm{nA})$ injected via the recording electrode in either MPN reduces firing frequency in the uninjected MPN. 
Figure 7. Enhancement of the pyloric rhythm by intracellular MPN stimulation. Pyloric rhythm recorded extracellularly from lateral ventricular ( $l v n)$ nerve and median ventricular ( $m v n)$ nerve, and intracellularly from LP neuron. Large, rhythmically active pyloric unit in mvn that appears following onset of MPN stimulation is the inferior cardiac (IC) constrictor motor neuron. Bottom trace shows intracellular MPN recording. MPN stimulated with intracellularly injected depolarizing current through the recording clectrode (firing frequency, $30 \mathrm{~Hz}$ ).

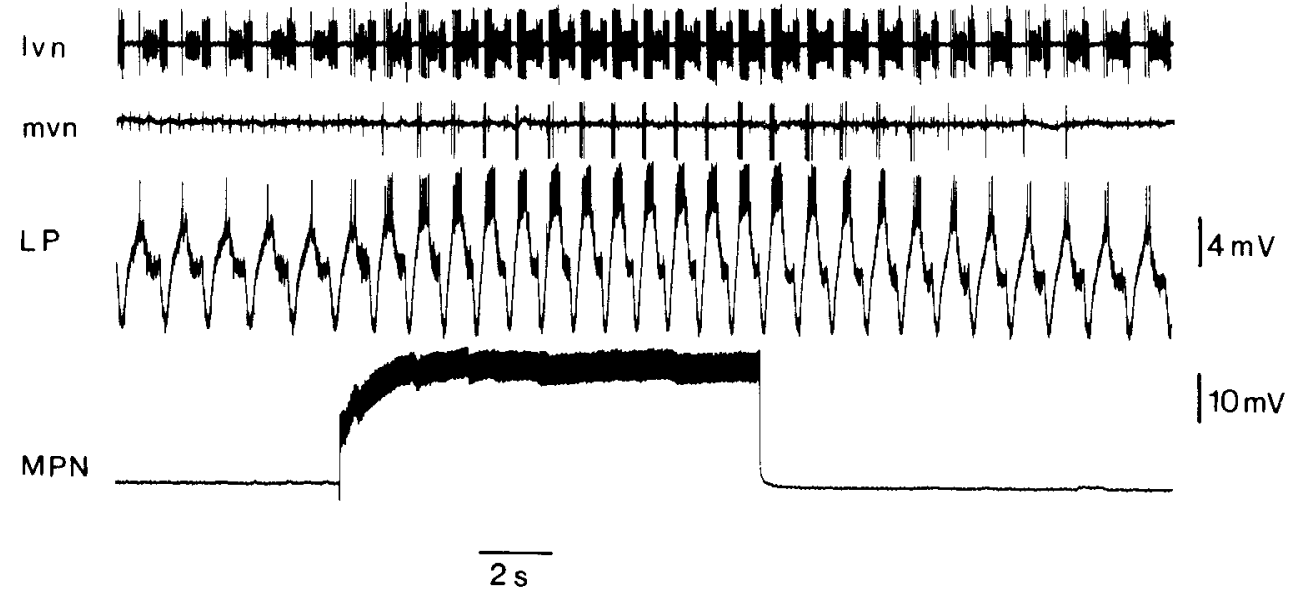

cellular recording from the lateral pyloric (LP) motor neuron (also seen as the largest amplitude spike on the lvn). The bottom trace is an intracellular recording from the soma of MPN. These simultaneous recordings show that depolarizing MPN with intracellular current injection increased the frequency of the pyloric rhythm by $35 \%$, from 0.83 to $1.12 \mathrm{~Hz}$, and enhanced both the amplitude of the rhythmic slow wave oscillations by $32 \%$ $(7.6-10 \mathrm{mV})$ and the associated impulse bursts recorded in the LP neuron by $630 \%$ ( 1 impulse/burst to 7.3 impulses/burst). Also evident is the activation of rhythmic impulse activity in the inferior cardiac (IC) motor neuron, seen in the mvn recording. This enhanced pyloric rhythm developed slowly and persisted after the stimulation ended. As in Figure 7, the peak response to MPN stimulation in already rhythmic preparations was reached after the first 2-4 sec of stimulation. This peak response was then maintaincd until MPN stimulation was ended. Prestimulus pyloric activity levels were not regained until many seconds after MPN activation ended. For example, after $10 \mathrm{sec}$ of MPN stimulation, the pyloric rhythm remained above prestimulus levels for approximately $7-10 \mathrm{sec}$ longer. In the preparations studied here, the gastric mill rhythm, another motor pattern produced in the STG by a different neural ensemble (Selverston and Moulins, 1987), was not spontaneously active, nor did MPN stimulation initiate the gastric mill rhythm.

Simultaneous intracellular recordings of both MPNs indicated that their effects on the pyloric rhythm were indistinguishable (Fig. 8). Stimulating both MPNs simultaneously tended to have a stronger effect on the pyloric rhythm than did stimulating either one alone (data not shown).

\section{MPN produces plateau potentials}

At lower levels of intracellular depolarizing current injection ( $<1 \mathrm{nA}$ ), MPN typically fired impulses tonically. However, at higher levels of current injection $(>1 \mathrm{nA})$ or after repeated intracellular stimulation, MPN also exhibited plateau potentials that often outlasted the duration of stimulation for many seconds. For example, during the 2-sec-long MPN stimulation in Figure 9, a plateau potential was generated in MPN that was maintained for $9 \mathrm{sec}$ after the depolarizing current injection was terminated. During this time, the MPN membrane potential remained at a depolarized level $(-20 \mathrm{mV})$ and underwent smallamplitude, high-frequency oscillations. It then spontaneously repolarized to its resting potential of $-40 \mathrm{mV}$. This activity evidently produced MPN impulse activity that propagated to the STG because the enhanced pyloric rhythm that occurred during MPN stimulation was maintained and did not begin to decrement to the prestimulus state until MPN returned to its resting potential.

\section{Discussion}

Proctolin has been found in hundreds to thousands of neurons in arthropod species (Bishop and O'Shea, 1982; Siwicki and Bishop, 1986; Nässel and O'Shea, 1987). Some of these proc-
Figure 8. Both MPNs have similar effects on pyloric rhythm. With simultaneous intracellular recordings of both MPNs $\left(M P N_{1}\right.$ and $\left.M P N_{2}\right)$, each MPN was stimulated individually (average firing frequency of stimulated MPN: $\mathrm{MPN}_{2}, 18 \mathrm{~Hz} ; \mathrm{MPN}_{1}, 20 \mathrm{~Hz}$ ). In addition to the enhanced pyloric rhythm, note the increased tonic impulse activity, in each case, of the unstimulated MPN.
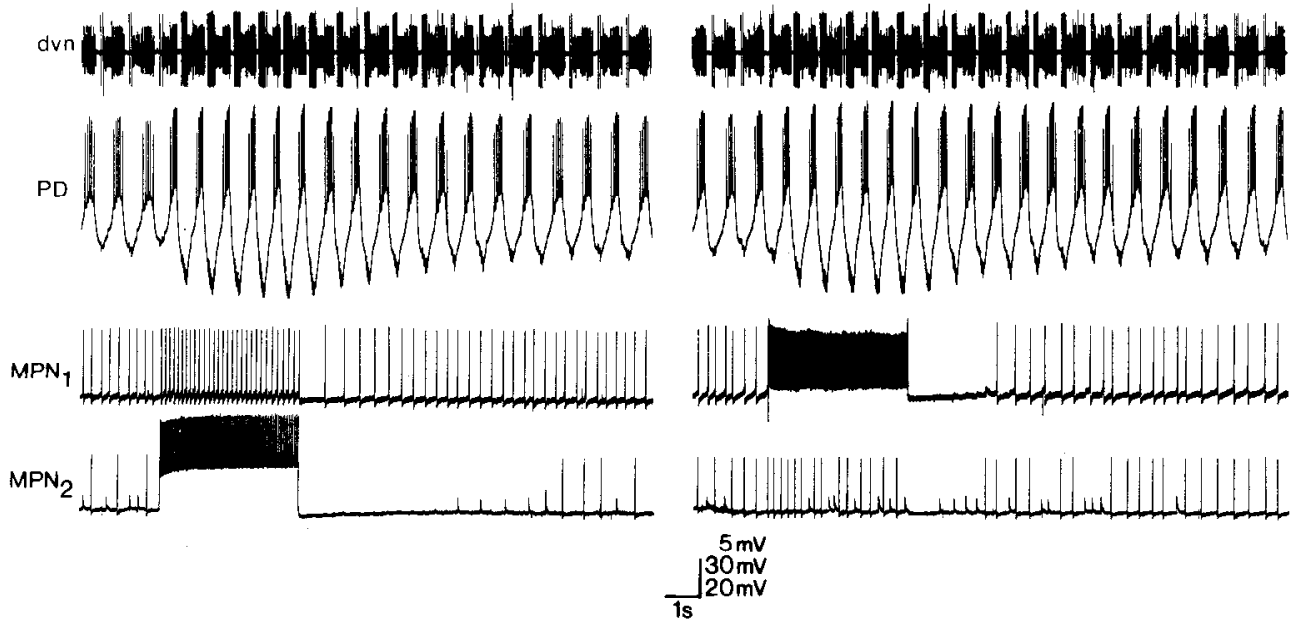

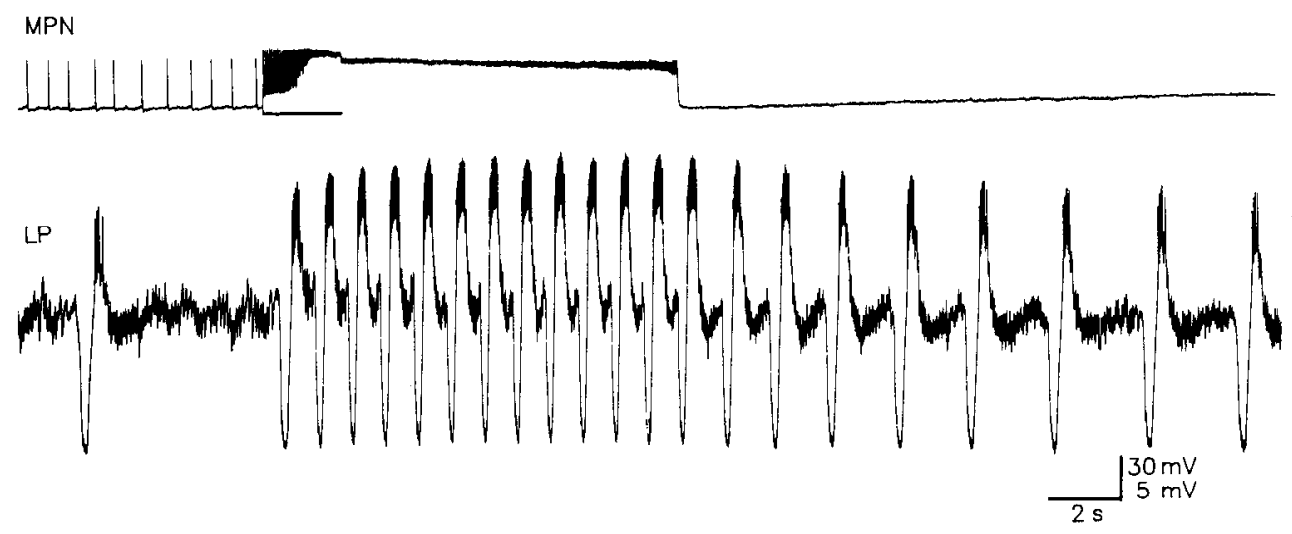

Figure 9. Endogenous plateau potentials gencrated by MPN in response to intracellular depolarizing current injection. Following termination of a $2 \mathrm{sec}$ intracellular depolarizing current injection (bar), the MPN membrane potential remained depolarized ( -16 to -22 $\mathrm{mV}$ ) and fired high-frequency impulses for another $9 \mathrm{sec}$. MPN membrane potential spontaneously repolarized to rest $(-40 \mathrm{mV})$.

tolin-containing neurons are motor neurons (Adams and O'Shea, 1983; Bishop et al., 1984), and some are sensory neurons (Pasztor and Bush, 1987). However, thus far, the function of most of the proctolin-containing ncurons found in arthropods is unknown. In fact, the MPNs are among the first proctolin-containing neurons whose function is at least partially understond.

We know that the MPNs are capable of activating the pyloric rhythm of the STG. The apparent electrical coupling between the MPNs suggests that they may normally act together to excite the pyloric rhythm. This possibility is reinforced by the identical, bilaterally symmetric branching pattern of both MPNs.

Knowing that the MPNs activate the pyloric rhythm raises other questions concerning the physiological role of these neurons in the behavior of the animal. For example, we do not yet know how many other motor patterns in the animal the MPNs influence. In the lobster, Panulirus interruptus, proctolin influences the gastric and cardiac sac rhythms as well as the pyloric rhythm (Marder et al., 1986; Dickinson and Marder, 1988, 1989; Heinzel and Selverston, 1988). Other identified modulators of the pyloric rhythm, the anterior pyloric modulator neuron (APM; Nagy and Dickinson, 1983) and the gastro-pyloric receptor (GPR) cells (Katz, 1989), have been recently shown to also interact with the gastric system (Dickinson, et al., 1988; Nagy et al., 1988; Katz, 1989). It will be interesting to determine whether the MPNs, like proctolin, APM, and GPR, are involved in the coordination of several different neuronal circuits. Thus far, the gastric rhythm in the crab has proven impossible to activate reliably by any means, including MPN stimulation, when inputs from the CGs are removed or blocked. It is possible that MPN will influence and/or activate gastric activity in the crab when commissural inputs are present.

We know little of the pathways that lead to the activation of the MPNs during normal behavior in the animal. From what we already know of the projection patterns of the MPNs, it is clear that, in principle, the MPNs might receive synaptic inputs in a variety of locations, including the CGs, OG, and STG. Additionally, whereas our LY injections were limited to showing the projection patterns of the MPN within the stomatogastric nervous system, it is possible that the MPNs also extend processes into other ganglia of the animal as well, out of the range of the performed LY fills. In that case, the MPNs might also receive, and make, synaptic contacts in still other ganglia. Therefore, in these isolated preparations we may have removed some of the normal sources of synaptic inputs to the MPNs.

It is always of interest to determine whether an activating input to a motor system receives feedback from the motor sys- tem it activates. In preparations containing only the $O G$ and STG, the MPNs do not routinely receive synaptic feedback directly from the pyloric network. It remains possible, however, that MPN might receive thythmic, pyloric-timed input in more intact preparations. For example, the histaminergic $\mathrm{C} 2$ neuron in Aplysia is similar to MPN in that it modulates a rhythmic motor pattern in the isolated nervous system but is not itself rhythmically active in such preparations (Weiss et al., 1986). It also has peripherally directed processes. In more intact preparations, during rhythmic movements mediated by the motor pattern modulated by $\mathrm{C} 2$, this neuron does undergo rhythmic activity that is time-locked to these movements. Like neuron C2, MPN has peripherally directed processes, which leaves open the possibility that it too may be affected by rhythmic muscle activity. This may result either directly, perhaps via peripheral stretch-sensitive dendrites, or indirectly, from a pathway originating in a sensory neuron with peripheral processes that we rountinely fail to maintain in our preparations.

Alternatively, the lack of feedback to MPN in the isolated nervous system may indicate that, when activated physiologically, MPN is not phasically active with the pyloric rhythm, but instead is either tonically driven or activated in a way that enables MPN activity to outlast that of its input. The latter possibility is supported by the finding that MPN can generate plateau potentials in response to current injection. Certainly, if MPN interacts with more than just the pyloric network neurons, it might be less than optimal to have it receive strong cycle-bycycle timing information from the pyloric rhythm.

Many systems contain neurons that have been called "command" or "gating" neurons, that share with MPN the ability to initiate and drive rhythmic motor patterns (e.g., Gillette et al., 1978; Kristan and Weeks, 1983; Benjamin et al., 1985; Nusbaum, 1986). MPN shares with gating neurons the ability to initiate and drive rhythmic motor activity but differs somewhat from some of these neurons in several respects. Gating neurons are generally interneurons (Kupfermann and Weiss, 1978; Brodfuehrer and Friesen, 1986). MPN extends processes out peripheral nerves, as well as into the STG, and does not appear to be exclusively an interneuron. Whether it is performing a sensory, motor, or modulatory function in the periphery remains to be determined. A second distinct feature of MPN is that, besides performing a role as a gating element, MPN also has modulatory effects on the pyloric rhythm that outlast MPN stimulation (Nusbaum and Marder, 1989). For these reasons, it seems that the MPNs may not fit neatly into any of the classification schemes for this kind of neuron in current use. 
It remains to be detcrmined whether the 2 MPNs are entirely responsible for the profusion of proctolin-immunoreactive processes within the STG neuropil (Marder et al., 1986). It is possible that one or more proctolinergic neurons with somata elsewhere in the animal may also project into the STG. Should MPN prove to have no action on the gastric and cardiac sac rhythms while proctolin does, this would potentially indicate that (1) proctolin released from MPN may reach only restricted targets within the neuropil of the STG, and (2) another proctolinergic input to the STG likely exists.

The STG has been a useful preparation for the study of how rhythmic motor patterns are generated and modulated by peptides. Previous to our identification of the MPNs, we have been forced to restrict ourselves to the study of exogenously applied peptides (Hooper and Marder, 1987; Marder, 1987; Nusbaum and Marder, 1988a). We now can use the MPNs to define more clearly the modulation of a rhythmic neural network by neurally released peptide, and compare and contrast these effects with those of exogenous peptide applications (Nusbaum and Marder, 1989).

\section{References}

Adams, M. E., and M. O'Shea (1983) Peptide cotransmitter at a neuromuscular junction. Science $221: 286-289$.

Beltz, B., and E. A. Kravitz (1983) Mapping of serotonin-like immunoreactivity in the lobster nervous system. J. Neurosci. 3: 585602.

Benjamin, P. R., C. J. H. Elliott, and G. P. Ferguson (1985) Neural network analysis in the snail brain. In Model Neural Networks and Behavior, A. I. Selverston, ed., pp. 87-108, Plenum, New York.

Bishop, C. A., and M. O'Shea (1982) Neuropeptide proctolin (H-ArgTyr-Leu-Pro-Thr-OH): Immunocytochemical mapping of neurons in the central nervous system of the cockroach. J. Comp. Neurol. 207: 223-238.

Bishop, C. A., M. O'Shea, and R. J. Miller (1981) Neuropeptide proctolin (H-Arg-Tyr-Leu-Pro-Thr-OH): Immunological detection and neuronal localization in insect central nervous system. Proc. Natl. Acad. Sci. USA 78: 5899-5902.

Bishop, C. A., J. J. Wine, and M. O'Shea (1984) Neuropeptide proctolin in postural motoneurons of the crayfish. J. Neurosci. 4: 20012009.

Bishop, C. A., J. J. Wine, F. Nagy, and M. R. O'Shea (1987) Physiologial consequences of a peptide cotransmitter in a crayfish nervemuscle preparation. J. Neurosci. 6: 1769-1779.

Brodfuehrer, P. D., and W. O. Friesen (1986) Initiation of swimming activity by trigger neurons in the leech subesophageal ganglion. I. Output connections of $\operatorname{Tr} 1$ and $\operatorname{Tr} 2$. J. Comp. Physiol. 159: 489-502.

Callaway, J. C., B. Masinovsky, and K. Graubard (1987) Co-localization of $\mathrm{SCP}_{\mathrm{b}}$-like and FMRFamide-like immunoreactivities in crustacean nervous systems. Brain Res. 405: 295-304.

Davis, N. T., S. G. Velleman, T. Kingan, and H. Keshishian (1989) Identification and distribution of a proctolin-like neuropeptide in the nervous system of the gypsy moth, Lymantria dispar, and in other Lepidoptera. J. Comp. Neurol. (in press).

Dekin, M. S., G. B. Richerson, and P. A. Getting (1985) Thyrotropinreleasing hormone induces rhythmic bursting in neurons of the nucleus tractus solitarius. Science 229: 67-69.

Dickinson, P. S., and E. Marder (1988) Peptides modulate the lobster cardiac sac rhythm. Soc. Neurosci. Abstr. 14: 30.

Dickinson, P. S., and E. Marder (1989) Peptidergic modulation of a multi-oscillator system in the lobster. I. Activation of the cardiac sac rhythm by the neuropeptides proctolin and red pigment concentrating hormone. J. Neurophysiol. (in press).

Dickinson, P. S., F. Nagy, and M. Moulins (1988) Control of central pattern generators by an identified neurone in Crustacea: Activation of the gastric mill motor pattern by a neurone known to modulate the pyloric network. J. Exp. Biol. 136: 53-87.

Gillette, R., M. P. Kovac, and W. J. Davis (1978) Command neurons in Pleurobranchaea receive synaptic feedback from motor network they excite. Science 199: 798-801.
Goldberg, D., M. P. Nusbaum, and E. Marder (1988) Substance P-like immunoreactivity in the stomatogastric nervous systems of the crab Cancer borealis and the lobsters Panulirus interruptus and Homarus americanus. Cell Tissue Res. 252: 515-522.

Heinzel, H.-G., and A. I. Selverston (1988) Gastric mill activity in the lobster. III. Effects of proctolin on the isolated central pattern generator. J. Neurophysiol. 59: 566-585.

Hökfelt, T., D. Millhorn, K. Seroogy, Y. Tsuruo, S. Ceccatelli, B. Lindh, B. Meister, T. Melander, M. Schalling, T. Bartfai, and L. Terenius (1987) Coexistence of peptides with classical transmitters. Experientia 43: 768-780.

Hooper, S. L., and E. Marder (1984) Modulation of a central pattern generator by two neuropeptides, proctolin and FMRFamide. Brain Res. 305: 186-191.

Hooper, S. L., and E. Marder (1987) Modulation of the lobster pyloric rhythm by the peptide proctolin. J. Neurosci. 7: 2097-2112.

Jan, Y. N., C. W. Bowers, D. Branton, L. Evans, and L. Y. Jan (1983) Peptides in neuronal function: Studies using autonomic ganglia. Cold Spring Harbor Symp. Quant. Biol. 48: 363-374.

Katz, P. S. (1989) Motor Pattern Modulation by Serotonergic Sensory Cells in the Stomatogastric Nervous System. Ph.D. dissertation, Cornell University.

Krieger, D. T., M. J. Brownstein, and J. B. Martin (1983) Brain Peptides, Wiley, New York.

Kristan, W. B., Jr., and J. C. Weeks (1983) Neurons controlling the initiation, generation and modulation of leech swimming. In Neural Origin of Rhythmic Movement, A. Roberts and B. L. Roberts, eds., pp. 243-260, Society for Experimental Biology Symposium XXXVII. Cambridge U. P., Cambridge, UK

Kuhlman, J. R., C. Li, and R. L. Calabrese (1985) FMRFamide-like substances in the leech. II. Bioactivity on the heartbeat system. J. Neurosci. 5: 2310-2317

Kupfermann, I., and K. R. Weiss (1978) The command neuron concept. Behav. Brain Sci. 1: 3-39.

Li, C., and R. L. Calabrese (1987) FMRFamide-like substances in the leech. III. Biochemical characterization and physiological effects. J. Neurosci. 7: 595-603.

Mackey, S., and T. J. Carew (1983) Locomotion in Aplysia: Triggering by serotonin and modulation by bag cell extract. J. Neurosci. 3: 14691477

Marder, E. (1987) Neurotransmitters and neuromodulators. In The Crustacean Stomatogastric System, A. I. Selverston and M. Moulins, eds., pp. 263-300, Springer-Verlag, Heidelberg.

Marder, E., S. L. Hooper, and K. K. Siwicki (1986) Modulatory action and distribution of the neuropeptide proctolin in the crustacean stomatogastric nervous system. J. Comp. Neurol. 243: 454-467.

Marder, E., R. L. Calabrese, M. P. Nusbaum, and B. Trimmer (1987) Distribution and partial characterization of FMFRamide-like peptides in the stomatogastric nervous systems of the rock crab, Cancer borealis, and the spiny lobster, Panulirus interruptus. J. Comp. Neurol. 259: $150-163$.

Mulloney, B., L. D. Acevedo, and A. G. Bradbury (1987) Modulation of the crayfish swimmeret rhythm by octopamine and the neuropeptide proctolin. J. Neurophysiol. 58: 584-597.

Murphy, A. D., K. Lukowiak, and W. K. Stell (1985) Peptidergic modulation of patterned motor activity in identified neurons of Helisoma. Proc. Natl. Acad. Sci. USA 82: 7140-7144.

Nagy, F., and P. S. Dickinson (1983) Control of a central pattern generator by an identified modulatory interneurone in Crustacea. I. Modulation of the pyloric motor output. J. Exp. Biol. 105: 33-58.

Nagy, F., P. S. Dickinson, and M. Moulins (1988) Control by an identified modulatory neuron of the sequential expression of plateau properties of and synaptic inputs to a neuron in a central pattern generator. J. Neurosci. 8: 2875-2886.

Nässel, D. R., and M. O'Shea (1987) Proctolin-like immunoreactive neurons in the blowfly central nervous system. J. Comp. Neurol. 265 . $437-454$

Nusbaum, M. P. (1986) Synaptic basis of swim initiation in the leech. III. Synaptic effects of serotonin-containing interneurones (cells 21 and 61) on swim CPG neurones (cells 18 and 208). J. Exp. Biol. 122. 303-321.

Nusbaum, M. P., and E. Marder (1987) A newly identified modulatory proctolin-containing neuron (MP neuron) in the stomatogastric nervous system of the crab, Cancer borealis. Soc. Neurosci. Abstr. 13: 1257.

Nusbaum, M. P., and E. Marder (1988a) A neuronal role for a crus- 
tacean red pigment concentrating hormone-like peptide: Neuromodulation of the pyloric rhythm in the crab, Cancer borealis. J. Exp. Biol. 135: 165-181.

Nusbaum, M. P., and E. Marder (1988b) State-dependent modulation of the crab pyloric rhythm by modulatory proctolin-containing neurons. Soc. Neurosci. Abstr. 14: 534.

Nusbaum, M. P., and E. Marder (1989) A modulatory proctolincontaining neuron (MPN). II. State-dependent modulation of rhythmic motor activity. J. Neurosci. 9: 1600-1607.

O'Shea, M., and M. Schaffer (1985) Neuropeptide function: The invertebrate contribution. Annu. Rev. Neurosci. 8: 171-198.

Pasztor, V. M., and B. M. H. Bush (1987) Peripheral modulation of mechanosensitivity in primary afferent neurons. Nature 326: 793795.

Polak, J. M., and S. R. Bloom, eds. (1987) Regulatory peptides. Fxperientia 43: 723-850.

Selverston, A. I., and M. Moulins (1987) The Crustacean Stomatogastric System, Springer-Verlag, Berlin.
Sigvardt, K. A., B. S. Rothman, R. O. Brown, and E. Mayeri (1986) The bag cells of Aplysia as a multitransmitter system: Identification of alpha bag cell peptide as a second neurotransmitter. J. Neurosci. 6: 803-813.

Siwicki, K. K., and C. A. Bishop (1986) Mapping of proctolin-like immunoreactivity in the nervous systems of the lobster and crayfish. J. Comp. Neurol. 243: 435-453.

Sossin, W. S., M. D. Kirk, and R. H. Scheller (1987) Peptidergic modulation of neuronal circuitry controlling feeding in Aplysia. J. Neurosci. 7: 671-681.

Turrigiano, G., and A. I. Selverston (1987) Presence and release of a $\mathrm{CCK} /$ gastrin-like molecule in the lobst $r$ stomatogastric ganglion. Soc. Neurosci. Abstr. 13: 1257.

Weiss, K. R., E. Shapiro, and I. Kupferr tann (1986) Modulatory synaptic actions of an identified histaminergic neuron on the serotonergic metacerebral cell of Aplysia. J. Neurosci. 6: 2393-2402. 